\title{
Anatomy of the Brachial Plexus: A Rare Variation in the Laboratory of Anatomy of Bamako (Mali)
}

\author{
Babou Ba ${ }^{*}$, Abdoulaye Kanté1,2, Drissa Traoré2, Bréhima Bengaly², Mariam Daou ${ }^{3}$, \\ Bréhima Coulibaly², Drissa Ouattara², Siaka Diallo², Siaka Diakité1, Moumouna Koné1, Tata Touré1, \\ Cheickh Tidiane Diallo1, Ousmane Ibrahim Touré2, Birama Togola², Nouhoum Ongoïba ${ }^{1,2}$
}

\author{
${ }^{1}$ Laboratory of Anatomy of the Faculty of Medicine and Odontostomatology, Bamako, Mali \\ ${ }^{2}$ Service of Surgery B. CHU Point G, Bamako, Mali \\ ${ }^{3}$ Service of Neurology, CHU Gabriel Touré, Bamako, Mali \\ Email: *babouba20022000@y ahoo.fr
}

How to cite this paper: Ba, B., Kanté, A., Traoré, D., Bengaly, B., Daou, M., Coulibaly, B., Ouattara, D., Diallo, S., Diakité, S., Koné, M., Touré, T., Diallo, C.T., Touré, O.I., Togola, B. and Ongoïba, N. (2019) Anatomy of the Brachial Plexus: A Rare Variation in the Laboratory of Anatomy of Bamako (Mali). Forensic Medicine and Anatomy Research, 7, 8-12.

https://doi.org/10.4236/fmar.2019.71002

Received: October 3, 2018

Accepted: December 5, 2018

Published: January 2, 2019

Copyright $\odot 2019$ by authors and Scientific Research Publishing Inc. This work is licensed under the Creative Commons Attribution International License (CC BY 4.0).

http://creativecommons.org/licenses/by/4.0/

\section{(c) (i) Open Access}

\begin{abstract}
The brachial plexus (BP), established by the lap twigs of the last four cervical nerves and the first thoracic nerve, assures the driving and sensory innervation of the thoracic member. We bring back a case of rare anatomical variation of the brachial plexus. It is a 34-year-old corpse dissected in the laboratory of anatomy of the Faculty of Medicine and Odontostomatology of Bamako in September 2017. The lap twig of the fourth cervical root (C4) participated in the constitution of the brachial plexus. The superior trunk was normally constituted. The average trunk was formed by the cervical roots $\mathrm{C} 7$ and C8 instead of only C7. And consequently the inferior trunk was constituted by the thoracic root $\mathrm{T} 1$. The posterior beam was only formed by the posterior branches of the superior and more average trunk. The medial beam was formed by all of the inferior trunk which did not give posterior branch for the formation of the posterior beam. The variations of the brachial plexus could entrain failures in the loco regional anesthesia of the brachial plexus.
\end{abstract}

\section{Keywords}

Anatomy, Brachial Plexus, Variation, Anesthesia, Surgery

\section{Introduction}

The brachial plexus (BP), constituted by the lap twigs of the last four cervical nerves and the first thoracic nerve, assures the driving and sensory innervation 
of the thoracic member [1]. The hurts of the brachial plexus are frequent [2] [3]. It is about strains or break by obstetric drive or by trauma of the cervical rachis, the slipped discs and the cervical degenerative osteoarthritis. The magnetic resonance imaging (MRI) is the examination of reference imaging for the exploration of the brachial plexus [4].

The microsurgery considerably improved the results of the surgery of the hurts of the brachial plexus [3].

We report a case of rare anatomical variation of the brachial plexus.

\section{Case Report}

It is about a 34-year-old corpse dissected in the laboratory of anatomy of the Faculty of Medicine and Odontostomatology of Bamako in September 2017.

The way at first was cervical and brachial. For that purpose, three sections were made. The first section, cervical, went of the mandible to the sternal incisure on the median line.

Second, side, leaving of thesterna incisure (lower extremity of the first section), followed the previous edge of the collarbone until the height of the joint acromio-clavicular, this section was extended then at the level of the third way of the arm. The third section went of the superior extremity of the first one to the process mastoid. On the median line, the cervical section was extended on the thorax until the process xiphoid. The dissection was led by the skin to muscles. The cutaneous shred was dissected then pulled down outside. The parade scalenique established a mark of identification of roots.

Muscles scalene were ruled out to dissect and highlight roots. In the region axillary the pectoral big and small muscles which established the plan of lap cover of the BP, were cut to dissect well the beams and the terminal branches. The artery axillary and the coraco-brachial muscle were marks important for the identification of the musculo-cutaneous and median nerves. The radial nerve and the nerve axillary were looked for behind the artery axillar.

Nerves ulnar, cutaneous medial of the forearm and cutaneous medial of the arm were looked for inside of the artery axillary. To highlight roots up to the second thoracic root (T2), we proceeded to the ablation of the collarbone and the dome pleural was repulsed caudally. The muscle sub-keyboard established a lap important mark. Behind, the dorsal round and big round, small sub-scapular, big muscle established the floor of the BP. The dissection was pursued until the third way of the arm. So all the branches of the BP were dissected by the cervical region in the arm.

Specimens were photographed with a leading telephone Samsung Galaxia Grand outdo.

\subsection{At the Level of the Root of the Brachial Plexus}

The lap twig of the fourth cervical root (C4) participated in the constitution of the brachial plexus (Figure 1). 

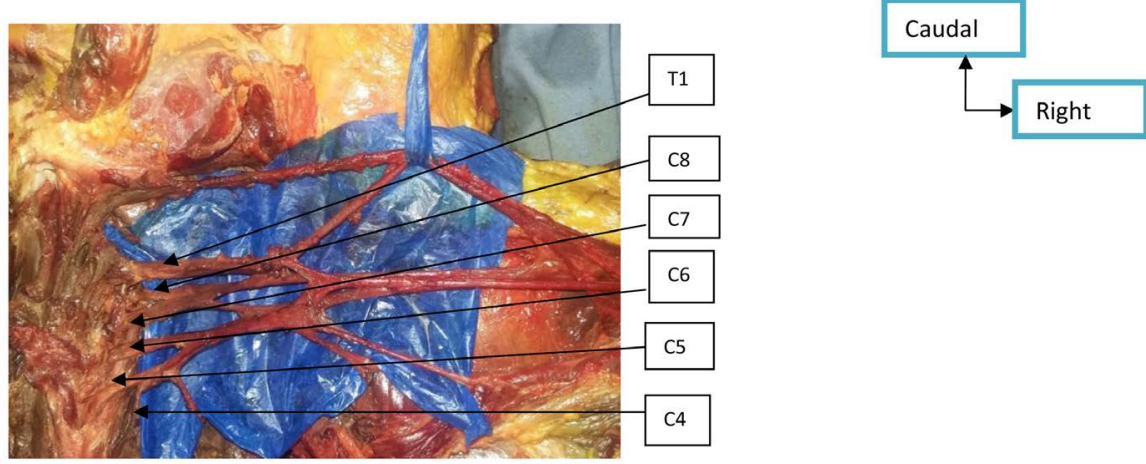

Figure 1. Participation of $\mathrm{C} 4$ in the constitution of the BP. Photography: laboratory of anatomy of Bamako. C4 $=$ The previous twig of the 4th cervical root; C5 = The previous twig of the 5th cervical root. $\mathrm{C} 6=$ The previous twig of the 6 th cervical root; $\mathrm{C} 7=$ The previous twig of the 7 th cervical root. $\mathrm{C} 8=$ The previous twig of the 8 th cervical root; T1 $=1$ st thoracic nerve.

\subsection{Constitution of the Trunks of the Brachial Plexus}

The superior trunk was normally constituted. The average trunk was formed by the cervical roots $\mathrm{C} 7$ and $\mathrm{C} 8$ instead of only C7. And consequently the inferior trunk was constituted by the thoracic root $\mathrm{T} 1$ (Figure 1).

\subsection{Training of the Beams of the Brachial Plexus}

The later beam was only formed by the later branches of the superior and more average trunk. The beam medial was formed by all of the inferior trunk which did not give posterior branch for the training of the posterior beam (Figure 2).

\subsection{Terminal Branches of the Brachial Plexus}

We found that:

The low birth of the musculo-cutaneous nerve,

The high birth of the cutaneous medial nerve of the arm.

The nerve ulnar, the branch medial of the median nerve, the cutaneous medial nerve of the arm and the cutaneous medial nerve of the front arm arose from the inferior trunk (Figure 2).

We did not note participation of $\mathrm{T} 2$ in the constitution of the brachial plexus.

\section{Discussion}

\subsection{Participation of the Cervical Root $\mathrm{C} 4$ in the Constitution of the Brachial Plexus}

There are numerous variations of constitution of the brachial plexus. The most frequent are the brachial said plexus "prefixed" with the cooperation of the previous branch of $\mathrm{C} 4$. In our observation, the lap twig of the fourth cervical root (C4) participated in the constitution of the brachial plexus. It was $41 \%$ in the series of B. Senecail [5], 30.4\% in the series of Ongoïba on 23 dissections. Kerr [6] found $65.9 \%$ and $60 \%$ in two series of 56 and 54 cases while Lee [7] found only $22.4 \%$ of participation of $\mathrm{C} 4$ in the $\mathrm{BP}$ on 152 dissections. 


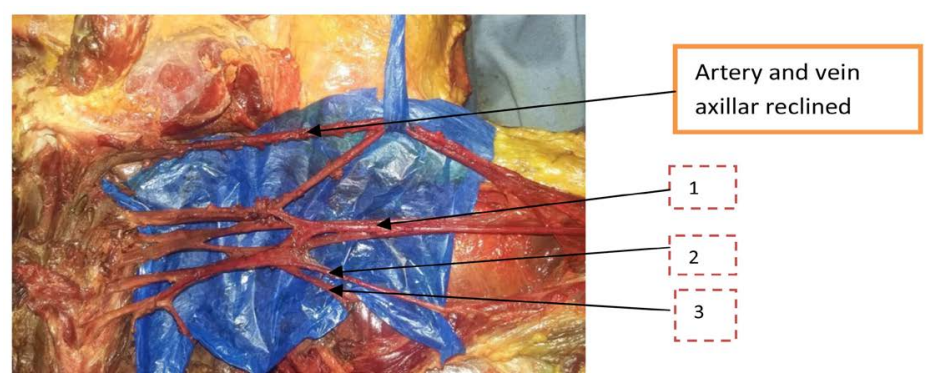

Figure 2. High Birth of the nerve musculo-cutané: 1) Median nerve, 2) Musculo-cutaneousnerve, 3) nerf axillar. Photograph: laboratory of anatomy of de Bamako.

The "postfixed" said brachial plexus with the cooperation of the previous branch of $\mathrm{T} 2$ is rarer, met in $5 \%$ of the cases [5]. In our observation, we did not find this participation.

\subsection{Variation Fascicular of the Brachial Plexus}

At the level fascicular, we found in our observation the following variations: The posterior beam was only formed by the posterior branches of the superior and more average trunk.

The side beam was normally constituted.

The medial beam was formed by all of the inferior trunk which did not give posterior branch for the formation of the posterior beam.

Ongoïba found two cases of variation fascicular of the brachial plexus on 23 cases of dissection. In the first variation he describes an abnormal fusion of three beams from where were born all the terminal branches. In its second variation, the pectoral small nerve had one is born low in the region of the beams.

\subsection{Terminal Branches}

The variations found at the level of the terminal branches concerned the low birth of the musculo-cutaneous nerve, the high birth of the cutaneous nerve medial of the arm. The branch medial of the median nerve, the cutaneous nerve medial of the arm and the cutaneous nerve medial of the front arms arose from the inferior trunk because this one formed the beam medial.

Ongoiba [3] found in $34.8 \%$ ( 8 cases on 23 dissections) of variations of the terminal branches and among these $13 \%$ concerned the unusual seat of the musculo-cutaneous nerve.

\section{Conclusion}

The variations of the brachial plexus could entrain failures in the loco regional anesthesia of the brachial plexus. The surgery of the lesional pathologies of the brachial plexus requires the perfect knowledge of its anatomical variations.

\section{Authorization of the Ethics Committee}

We, undersigned, authors of this article, give evidence to have received the 
authorization of the Ethics Committee of the Faculty of Medicine of Bamako.

\section{Conflicts of Interest}

We, authors of this article, declare that there is no conflict of interests.

\section{References}

[1] Pierre, K. (2015) Nerves of the Upper Limb. In: Clinical Anatomy, 4th Edition, Maloine, Paris, 293.

[2] Chevallier, J.M. and Vitte, E. (2015) The Spinal Marrow and the Spinal Nerves. In: Neuro-Anatomy, 2nd Edition, Lavoisier, Paris, 58.

[3] Ongoïba, N., Destrieux, C. and Koumaré, A.K. (2002) Anatomical Variations of the Brachial Plexus. Morphology, 86, 31-34.

[4] Rousset, J., Garetiera, M., Chinellato, S., Diouf, C.T., Barberot, C. and Feuvrier, Y. (2011) Anatomy of the Brachial Plexus in MRI. Journal of Radiology, 51, 193-220.

[5] Brizon, J. and Castaing, J. (1985) The Leaves of Anatomy. Fascicule VI Vessels of the Superior Limb. Maloine, Paris, 1-10.

[6] Brizon, J. and Castaing, J. (1985) The Leaves of Anatomy. Fascicule XIII Vessels of the Neck. Maloine, Paris, 1-11.

[7] Lee, H.Y., Chung, I.H., Sir, W.S., Hours, K., Hours, L. and Ko, J.S. (1992) Variations of the Lap Rummy of the Brachial Plexus. Newspaper of Korean Medical Science, No. 1, 19-24. 